\title{
Arrecadação e aplicação de recursos nas campanhas eleitorais
}

O presente artigo analisa a arrecadação e aplicação de recursos nas campanhas eleitorais. É importante refletir sobre o financiamento dos partidos e das campanhas eleitorais no Brasil, verificando quais as questões polêmicas que envolvem essa temática. Diante de todo o contexto histórico que envolve o sistema representativo brasileiro, algumas problemáticas surgem em âmbito eleitoral, despertando o interesse da doutrina e da sociedade, como é o caso da corrupção, que viola o patrimônio público e privilegia interesses particulares. Daí a importância de entender a problemática de como é realizado o financiamento de partidos e campanhas políticas no país?. Observa-se a discussão atual a respeito do investimento de recursos públicos para essa finalidade, sendo preciso identificar o que diz a doutrina a respeito do tema. Essa relação entre dinheiro e política sempre esteve marcada pela complexidade, principalmente em um estado democrático, no qual o cidadão passa a questionar ativamente o papel das instituições políticas na vida em coletividade. Os partidos políticos passam a competir por recursos, que são necessários para a sua própria existência. Assim, diante da importância de estudar cientificamente a questão, são sistematizados e analisados livros, artigos científicos e trabalhos acadêmicos que tratem do financiamento de campanha eleitoral.

Palavras-chave: Arrecadação; Aplicação; Recursos financeiros; Campanha eleitoral.

\section{Fundraising and investment in election campaigns}

This article analyzes the collection and application of resources in electoral campaigns. It is important to reflect on the financing of political parties and electoral campaigns in Brazil, verifying the controversial issues surrounding this theme. In view of the entire historical context surrounding the Brazilian representative system, some issues arise in the electoral sphere, arousing the interest of doctrine and society, such as corruption, which violates public assets and privileges particular interests. Hence the importance of understanding the problem of how political parties and campaigns are financed in the country?. The current discussion regarding the investment of public resources for this purpose is observed, and it is necessary to identify what the doctrine says about the theme. This relationship between money and politics has always been marked by complexity, especially in a democratic state, in which the citizen begins to actively question the role of political institutions in collective life. Political parties start to compete for resources, which are necessary for their very existence. Thus, given the importance of studying the issue scientifically, books, scientific articles and academic papers dealing with electoral campaign financing are systematized and analyzed.

Keywords: Collection; Application; Financial resources; Election campaign

Topic: Direito Eleitoral

Reviewed anonymously in the process of blind peer.
Received: 20/10/2019

Approved: 05/03/2020

Carlos Alberto Silva

Faculdade de Venda Nova do Imigrante, Brasil

betounit@hotmail.com

Referencing this:

SILVA, C. A.. Arrecadação e aplicação de recursos nas campanhas eleitorais. Scientiam Juris, v.8, n.1, p.1-11, 2020. DOI: http://doi.org/10.6008/CBPC2318-3039.2020.001.0001 


\section{INTRODUÇÃO}

O Direito Eleitoral brasileiro é marcado por discussões sociais e doutrinárias a respeito de questões complexas, como é o caso do financiamento de campanhas eleitorais. Santano (2016) esclarece que a aprovação da lei das eleições no 9.504/97, com o artigo 17, estabeleceu a necessidade de prestação de contas sobre os recursos usados em campanha eleitoral. O autor esclarece que a responsabilização é importante devido à importância de interferir no poder econômico que grandes empresas exercem no processo de sufrágio, gerando desequilíbrio na disputa entre partidos.

O Código Eleitoral, em seu artigo 237, veda qualquer forma de interferência econômica em campanhas, uma vez que o abuso de poder é proibido, cabendo à justiça eleitoral fiscalizar e acompanhar a campanha eleitoral. Os poderes legislativo e judiciário, buscam formas de coibir todos os desvios de recursos, bem como as fraudes cometidas pelos candidatos e partidos políticos. A preocupação com o funcionamento das campanhas eleitorais faz com que surjam discursões a respeito da importância de coibir a participação do setor privado nesse processo eleitoral, como forma de eliminar o Lobby, que antecede o período de eleições.

Sabe-se que esses grupos privados possuem interesses que podem ir de encontro ao bem comum. A sua interferência em ações políticas é um dos elementos que contribuem para o enfraquecimento da democracia. Os candidatos e partidos políticos devem informar ao Tribunal Superior Eleitoral, o valor gasto em campanha eleitoral, respeitando o artigo 18, da Lei no 9.504/97.

Surge a necessidade de refletir sobre essa problemática, verificando quais os requisitos legais para a arrecadação e aplicação de recursos nas campanhas eleitorais. Salgado (2014) esclarece que é importante que seja estipulado um valor máximo, de forma que os abusos dos gastos sejam impedidos. Através de pesquisa bibliográfica, sistematização e reflexão de livros, artigos científicos e trabalhos acadêmicos, o estudo procura entender essa questão inerente ao direito eleitoral brasileiro.

A Lei dos Partidos Políticos, Lei no 9.096 de 19 de setembro de 1995, responsabiliza os partidos pela informação da quantia suficiente para o financiamento da campanha eleitoral, sem que haja um teto máximo fixado pela Justiça Eleitoral. Daí a importância de estudar o tema e refletir sobre a sua relação com o abuso de poder econômico. O objetivo geral é analisar os requisitos legais para a arrecadação e a aplicação dos recursos nas campanhas eleitorais. $O$ desenvolvimento econômico se torna essencial para as instituições e para o próprio país, mas, torna-se necessário buscar alternativas para a diminuição da desigualdade social, cabendo aos governantes o papel de realizar as escolhas certas, com base nos interesses coletivos, sem qualquer influência de setores privados e individualidades.

\section{METODOLOGIA}

\section{Campanhas Eleitorais}

\section{Aspectos gerais}

O objetivo da campanha eleitoral é promover as propostas de governo dos candidatos e dos partidos 
políticos, visando o convencimento do eleitor a respeito de ações que são melhores apresentadas politicamente. Assim, busca-se angariar votos e a conquista de um cargo político. Essa campanha tem a finalidade de captação de eleitores.

Segundo Gonçalves (2016), a campanha política é uma forma de divulgar as metas dos partidos políticos, buscando o convencimento das pessoas a respeito da preparação do partido e do candidato para assumir o cargo almejado. Trata-se de uma manifestação livre de pensamento. Através dela, as pessoas são influenciadas a ter um determinado comportamento, que é a aceitação do partido ou do candidato. Para que ocorra de forma democrática, são estabelecidas limitações. Cabe à legislação eleitoral, a responsabilidade de regulamentar e estabelecer o seu período de realização.

É importante que a campanha política seja baseada no respeito ao princípio da razoabilidade, assegurando os direitos fundamentais dos indivíduos. O estudo da arrecadação e aplicação dos recursos na campanha eleitoral requer a análise do Código eleitoral e das Leis nㅇ 9.504, de 30 de setembro de 1997 e n은 11.300, de 10 de maio de 2006, bem como das Resoluções e Instruções do Tribunal Superior Eleitoral.

A campanha eleitoral é realizada pelos partidos, durante o período das eleições, envolvendo o uso de elementos de propaganda, que são estabelecidos pela legislação. O artigo 32, § 10 da Constituição Federal, estabelece que a competência para legislar sobre a matéria é da União. É imprescindível que o interesse popular prevaleça, devendo a legislação ser baseada na vontade popular. O artigo 30 da Constituição Federal de 1988, estabelece que os municípios podem suplementar a legislação eleitoral.

A campanha eleitoral tem como um dos elementos, a participação em debates, entrevistas e encontros, cabendo aos pré-candidatos e candidatos aproveitarem o espaço para expor seus projetos políticos. Os candidatos e partidos participam de várias atividades, durante a campanha eleitoral, realizando a propaganda de suas propostas de governo. Essa fase é essencial para que os eleitores conheçam as ações de trabalho e a defesa dos interesses partidários, refletindo sobre a melhor ação e tomando a sua decisão de voto (SANTANO, 2016).

A campanha eleitoral auxilia na criação da imagem popular do candidato perante o eleitor. A legislação eleitoral veda qualquer tipo de propaganda eleitoral antes do período estabelecido. Segundo Furtado (2014), não cumprir essa exigência legal acarreta multa para os candidatos e partidos políticos. Segundo o art. 3으, § 4ㅇ, da Resolução no 22.718, essas multas podem ser estabelecidas no valor de R\$ 21.282,00 (vinte e um mil duzentos e oitenta e dois reais) a $\mathrm{R} \$ \mathbf{5 3 . 2 0 5 , 0 0}$ (cinquenta e três mil duzentos e cinco reais) ou equivalente ao custo da propaganda.

Entre as questões que causam controvérsia, na campanha eleitoral, está a conhecida 'boca de urna', que tem sido bastante confundida no imaginário popular, uma vez que é possível o eleitor manifestar a sua vontade, mas sem interferir no direito de sufrágio dos demais cidadãos. Sabe-se que a liberdade é um dos pilares da Constituição, sendo essencial defendê-la. O art. 39, § 5.ำ II, da Lei no 9.504/97, estabelece o crime eleitoral de 'boca de urna', que é apontado por Cândido (2008), como dois momentos que ocorrem no dia da eleição.

O primeiro é visto como uma pesquisa realizada com o eleitor após a votação, tendo por finalidade 
a antecipação do resultado. Essa ação é permitida pelo Tribunal Superior Eleitoral e é constantemente divulgada pelos telejornais. Muitas vezes, serve para que o brasileiro não tenha ansiedade ao esperar pelos resultados oficiais. No segundo caso, pode-se dizer que é a campanha feita na última hora, quando o eleitor é abordado na porta dos colégios eleitorais, na tentativa de ser influenciado em relação ao seu voto.

A 'boca de urna' é realizada pelos cabos eleitorais, sendo uma prática comum no Brasil, fazendo parte da história do Direito Eleitoral. Trata-se de uma prática contemporânea de voto de cabresto, na qual se troca vantagens ou dinheiro pela vitória nas urnas. Esse tipo de ação é caracterizado como crime e está sujeita à sanção, sendo totalmente vedada durante a campanha eleitoral. Para Gonçalves (2016), ao realizar uma ação criminosa, o candidato ou o partido, está interferindo negativamente no resultado do pleito eleitoral, elegendo pessoas despreparadas para representar os interesses da coletividade, fazendo com que o poder econômico seja um elemento determinante da eleição.

Em relação à arrecadação e aplicação dos recursos em campanhas eleitorais, verifica-se que o uso do poder econômico pode interferir diretamente no resultado de uma eleição. Essa ação de cabos eleitorais e demais ativistas, influenciando a decisão de eleitores quando se dirigem à seção eleitoral, é vedada pelo artigo 39, § 5으, da Lei no 9.504/97, que estabelece o seguinte:

Art. 39. A realização de qualquer ato de propaganda partidária ou eleitoral, em recinto aberto ou fechado, não depende de licença da polícia [...]

$\S 5$ o Constituem crimes, no dia da eleição, puníveis com detenção, de seis meses a um ano, com a alternativa de prestação de serviços à comunidade pelo mesmo período, e multa no valor de cinco mil a quinze mil UFIR:

I - O uso de alto-falantes e amplificadores de som ou a promoção de comício ou carreata;

II - A arregimentação de eleitor ou a propaganda de boca de urna;

III - A divulgação de qualquer espécie de propaganda de partidos políticos ou de seus candidatos, mediante publicações, cartazes, camisas, bonés, broches ou dísticos em vestuário.

$\S 60$ É vedada na campanha eleitoral a confecção, utilização, distribuição por comitê, candidato, ou com a sua autorização, de camisetas, chaveiros, bonés, canetas, brindes, cestas básicas ou quaisquer outros bens ou materiais que possam proporcionar vantagem ao eleitor.

§ 70 É proibida a realização de showmício e de evento assemelhado para promoção de candidatos, bem como a apresentação, remunerada ou não, de artistas com a finalidade de animar comício e reunião eleitoral.

$\S 8$ ó É vedada a propaganda eleitoral mediante outdoors, sujeitando-se a empresa responsável, os partidos, coligações e candidatos à imediata retirada da propaganda irregular e ao pagamento de multa no valor de 5.000 (cinco mil) a 15.000 (quinze mil) UFIRs. (BRASIL, 1997).

Nota-se que a finalidade da legislação não é coibir os eleitores de manifestarem a sua vontade, mas de os cabos eleitorais, utilizando o poder econômico, atuarem de forma negativa na decisão das pessoas. Nesse contexto, não se trata de uma limitação da liberdade, mas justamente da sua defesa. Mas, para melhor entender a legislação supracitada, foi elaborada, pelo Tribunal Superior Eleitoral, a Resolução no 2.426, de 27.09.2006, regulamentou o art. 67 da Resolução 22.261/2006, permitindo a manifestação individual e silenciosa, pelo eleitor, da sua preferência por candidato ou partido. Entretanto, é vedada na campanha eleitoral a confecção, a utilização, a distribuição por comitê, candidato ou com a sua autorização, de 
camisetas, chaveiros, bonés, canetas, brindes, cestas básicas ou quaisquer outros bens ou materiais que possam proporcionar qualquer vantagem ao eleitor (Resolução TSE 22.261/2006, art. 8.ํ, § 4.). Historicamente, o Brasil é marcado pela troca de favores, presentes e benefícios, como promessa de campanha, sendo uma manipulação da opinião do eleitor.

A liberdade do eleitor é defendida atualmente, sendo necessário que a Justiça Eleitoral acompanhe esse processo de campanha e promova efetivamente a democracia. No entendimento de Furtado (2016), a legislação eleitoral veda o aliciamento, a coação ou a manifestação que objetive influenciar negativamente a vontade do eleitor. A manipulação, por meio de compra de votos é um problema que precisa ser combatido.

Percebe-se, então, que a campanha política, quando realizada no dia da eleição é considerada boca de urna. A finalidade do Direito Eleitoral é garantir que as eleições brasileiras sejam realizadas de acordo com os princípios básicos de promoção da democracia, fazendo com que o eleitor decida o que é melhor para a coletividade sem qualquer interferência negativa, que possa contribuir para a manipulação dos resultados.

\section{DISCUSSÃO TEÓRICA}

\section{Arrecadação e aplicação de recursos}

As leis eleitorais que regulamentam a arrecadação e a aplicação dos recursos em campanhas eleitorais, estão relacionadas à reflexão política e social a respeito da importância do poder econômico para o resultado eleitoral. O dinheiro gasto pelos candidatos e partidos pode contribuir para a aquisição de votos, principalmente por meios que promovem a desigualdade. É necessário refletir sobre as formas utilizadas por diferentes grupos para investimento em campanhas eleitorais, visando a troca de favores e colaborações, na elaboração das políticas públicas, recebendo benefícios após a eleição.

Faz-se necessário estabelecer uma forma de financiamento de campanha que busque assegurar o bem-estar coletivo. Assim, o mandato deve ser voltado para o interesse social, que deve ser bem representado pelos políticos após a eleição. Entre as medidas da Justiça Eleitoral está o combate da apropriação indevida de bens públicos. O limite de gasto ou financiamento público, não é suficiente para minimizar a vantagem que o poder econômico exerce.

O gasto de campanha na forma de propagandas seria, portanto, um mecanismo de sinalização dos candidatos ao eleitor, de modo que candidatos do tipo bom buscam se diferenciar para evitar a existência dos chamados equilíbrios pooling. Diante disso, a presença de propaganda eleitoral revela um trade-off para o bem-estar social: por um lado há o benefício informacional, já que em tese a informação permitiria a escolha de políticos melhores (dada a hipótese de que toda a informação transmitida é verdadeira, ou que há ao menos a chance de identificação de informações falsas).

Ante o exposto, verifica-se que o acompanhamento da arrecadação e aplicação dos recursos na campanha eleitoral se torna essencial para coibir o abuso econômico, por parte de candidatos e partidos. Analisando a prática social, observa-se que muitos eleitores procuram favores e recursos, em troca de seu voto. Para Costa (2016), a legislação de financiamento eleitoral impõe o limite de gastos, sendo discutida a questão do financiamento público de campanha, como forma de aumentar a eficácia da mesma, inviabilizando a troca de favores entre os grupos lobistas, fazendo com que os eleitores optem pelos 
candidatos mais preparados e com propostas governamentais voltadas para a coletividade.

A Resolução do Tribunal Superior Eleitoral no 23.575/2018, surge com a proposta de alterar a Resolução no 23.553/2017, do mesmo órgão, estabelecendo as regras de arrecadação e gastos de recursos por partidos políticos e candidatos nas campanhas eleitorais. Assim, torna-se necessária a prestação de contas. A inexistência de candidatura própria ou em coligação acarreta a inviabilidade de distribuição de recursos do Fundo Especial para outros partidos ou candidatos. Entre as mudanças mais expressivas, está a determinação para que os partidos políticos destinem, no mínimo, 30\% (trinta por cento) dos recursos totais, para campanhas de candidatas, conforme se analisa no art. 21, § 4ㅇ da Resolução TSE no 23.575/2018:

Art. $21[\ldots] \S 4$ 응 Os partidos políticos, em cada esfera, devem destinar ao financiamento de campanhas de suas candidatas no mínimo $30 \%$ dos gastos totais contratados nas campanhas eleitorais com recursos do Fundo Partidário, incluídos nesse valor os recursos a que se refere o inciso V do art. 44 da Lei no 9.096/1995 (Lei no 13.165/2015, art. 9ㅇ) [...].

Nota-se que 30\% (trinta por cento) dos recursos do Fundo Partidário devem ser investidos na campanha eleitoral de candidatas. O limite de gastos e a sua comprovação se tornam essenciais para a efetivação do sufrágio democrático. Com o advento da Lei no 13.165/2015 houve a fixação de um valor, cuja fixação estava relacionada à declaração dos candidatos em eleições anteriores. Em 06 de outubro de 2017 surge a Lei no 13.488, que altera regras de fixação desse limite, nas eleições gerais, definindo os valores em reais. Os artigos 5으, 60 e 7ํㅡ, da Lei 13.488/2017 estabelecem um limite de gastos, conforme se observa no quadro 1.

Quadro 1: Limites de gastos em Reais, na Lei 13.488/17.

\begin{tabular}{|l|l|l|}
\hline CARGO & PRIMEIRO TURNO & SEGUNDO TURNO \\
\hline Presidente da República & 70 milhões & 35 milhões \\
\hline Governador & Até 1 milhão de eleitores $-2.800 .000,00$ & $1.400 .000,00$ \\
& Até 2 milhões de eleitores- 4.900.000,00 & $2.450 .000,00$ \\
& Mais de 2 milhões de eleitores $-5.600 .000,00$ & $2.800 .000,00$ \\
& Mais de 4 milhões de eleitores $-9.100 .000,00$ & $4.550 .000,00$ \\
& Mais de 10 milhões de eleitores $-14.000 .000,00$ & $7.000 .000,00$ \\
& Mais de 20 milhões de eleitores $-21.000 .000,00$ & $10.500 .000,00$ \\
\hline Senador & Até 2 milhões de eleitores- 2.500.000,00 & \\
& Mais de 2 milhões de eleitores $-3.000 .000,00$ & \\
& Mais de 4 milhões de eleitores $-3.500 .000,00$ & \\
\hline Deputado Federal & Mais de 10 milhões de eleitores $-4.200 .000,00$ & \\
\hline Deputado Estado & Mais de 20 milhões de eleitores $-5.600 .000,00$ & \\
\hline
\end{tabular}

Fonte: Brasil (2017a).

O quadro 1 demostra os limites impostos pela Lei no 13.488/17 para o investimento em campanha eleitoral, nas três esferas. Os candidatos que arrecadam um valor superior podem transferi-lo para o partido, que por sua vez, redistribui entre os demais candidatos que concorrem a cargos distintos. Algumas mudanças ocorreram em relação à essa arrecadação dos recursos para campanhas eleitorais, com o acréscimo do financiamento coletivo pela internet, conhecido popularmente como 'vaquinha virtual'.

Outra forma inovadora de arrecadação de recursos para a campanha eleitoral, observada na Lei no 13.488/17, é a comercialização de bens e serviços, bem como a realização de eventos. A arrecadação de recursos através de financiamento coletivo tem como requisitos: O cadastro prévio do candidato ou partido 
na Justiça Eleitoral; Identificação do doador (nome e CPF); Publicação em sítio eletrônico dos dados do doador e dos valores recebidos; Emissão de recibo ao doador, pelo arrecadador, com cópia para a Justiça Eleitoral; Ampla ciência a candidatos e eleitores sobre as taxas administrativas cobradas pelo serviço; Conhecimento da fonte do recurso; Respeito aos prazos estabelecidos por lei.

Analisando os requisitos para a arrecadação de recursos através de financiamento coletivo, percebese que deve haver transparência e fiscalização por parte da Justiça Eleitoral, que por sua vez, é responsável pelo acompanhamento da prestação de contas. É essencial que essas doações sejam fiscalizadas, bem como a aplicação dos recursos durante a campanha eleitoral. Cabe ao arrecadador fornecer os recibos necessários para a comprovação do levantamento do recurso. Percebe-se que a lei veda o recebimento de recursos de fonte desconhecida.

Segundo Carvalho (2020) a arrecadação por meio de financiamento coletivo é realizada no décimo quinto dia do mês de maio do ano em que se realiza a eleição, sendo o recurso liberado para os candidatos após o seu registro de candidatura. No caso de não ser concretizada, o artigo 22-A, §§3ํe e 4ำ, Lei das Eleições, Lei no 9.504, de 30 de setembro de 1997, estabelece a necessidade de devolução do valor aos doadores. 0 recebimento de valores pela Internet, independente da natureza da doação, precisa ser informado à Justiça Eleitoral, dentro de um prazo de três dias, a partir do depósito. O arrecadador deve ser registrado, com inscrição no Cadastro Nacional de Pessoa Jurídica, possuindo uma conta bancária específica para essa finalidade. A partir desses requisitos, passa a emitir recibos, com os dados referentes a essa arrecadação.

Os recibos eleitorais são dispensados quando é possível comprovar a doação por meio de documento bancário que identifique o doador e seu cadastro de pessoa física. Nesse caso, não há a dispensa da prestação de contas, uma vez que se tem a comprovação necessária para a legalização da ação arrecadadora.

Todas as instituições financeiras que atendam aos critérios definidos na legislação específica e regulamentação espedida pelo Banco Central do Brasil, ficam autorizadas a participar das transações relativas às modalidades de arrecadação por meio da internet (art. 23, §8ะ, Lei no 9.504/97). A lei passou a prever a impossibilidade das instituições financeiras e de pagamento recusarem a utilização de cartões de débito e crédito como meio de doações eleitorais de pessoas físicas (art. 23, §9, Lei no 9.504/97). (OLIVEIRA, 2020).

A legislação eleitoral veda qualquer forma de arrecadação, cujo doador não seja identificado. No caso de instituições financeiras, não podem recusar o uso de cartões em doações eleitorais. O §6으, art. 23, da Lei no 9.504/97 sofreu alterações passando a prever a impossibilidade de rejeição das contas ou responsabilização dos candidatos por fraudes e erros que possam ocorrer nas doações, realizadas a través do meio virtual.

Em relação aos recibos eleitorais, eles devem ser emitidos em qualquer arrecadação de recursos, seja por meio digital ou não, uma vez que a comprovação dessa movimentação financeira precisa de comprovação obrigatória. No caso do documento eletrônico, se torna imprescindível que o doador seja identificado, pelo nome e pelo cadastro de pessoa física. Cabe aos candidatos emitir o recibo pelo Sistema de Prestação de Contas Eleitorais - SPCE, e os partidos pelo sistema de Prestação de Contas Anual - SPCA. É necessário que os dados a respeito da arrecadação sejam prestados em ordem cronológica ao seu recebimento. 
Quando os doadores que utilizam cartões de crédito, a legislação eleitoral exige que esse recibo seja realizado no momento em a doação é realizada. Caso se tenha o estorno ou desistência, é possível realizar o cancelamento. Os recibos eleitorais são em nome do titular, mesmo que a arrecadação seja realizada pelo vice candidato. Quando não observados os limites impostos pela legislação eleitoral, se tem a aplicação de multa. Em relação aos bens móveis, a doação é limitada a um valor de $\mathrm{R} \$ \mathbf{4 . 0 0 0 , 0 0}$ (quatro mil reais), por cedente. Os recursos utilizados para produzir material publicitário impresso devem estar registrados na prestação de contas, da pessoa responsável pelo pagamento.

Carvalho (2020) explica que é preciso abrir uma conta para essa finalidade, mesmo que não tenha arrecadação. Mas é essencial que ela seja exclusiva para a movimentação financeira desses recursos para a campanha eleitoral. O autor apresenta os requisitos previstos na Lei no 9.504/1997, art. 22, § 2ㅇ, como o caso de não haver agência bancária, quando houver renúncia ou desistência antes mesmo do início do prazo de arrecadação, mas com a necessidade de apresentação de extratos.

As doações físicas são limitadas, havendo multa por doação em excesso, nos casos em que o valor arrecadado é maior que o previsto em lei eleitoral. Cada doador deve doar até $\mathrm{R} \$ 40.000,00$ (quarenta mil reais), entre dinheiro, bens móveis, imóveis e prestação de serviços, conforme se observa no art. 23, §70, Lei no 9.504/97. A origem dos recursos para campanha eleitoral é diversificada, podendo ser próprios, doações financeiras de pessoas físicas e filiados, partidos políticos ou outros candidatos. Podem ainda ser realizados serviços e comercializados bens e promoção de eventos.

O próprio partido político pode utilizar recursos próprios, desde que a sua origem seja identificada, recebendo o nome de Fundo Partidário. Há ainda o Fundo Especial de Financiamento de Campanha. É permitida a locação de bens, móveis e imóveis, bem como a alienação deles. Para Oliveira (2019), a origem dos recursos pode ser por empréstimo, desde que seja contratado em instituições autorizadas pelo Banco Central do Brasil, devendo integrar o patrimônio dos candidatos no momento em realizam o registro de candidatura e possam ser pagos com os seus rendimentos, de acordo com a atividade econômica exercida.

A comprovação do empréstimo deve ocorrer de forma documentada, com base na legalidade e idoneidade, bem como a quitação, estando presente na prestação de contas final. Os arrecadadores devem comprovar a origem, conforme dispõe a Resolução TSE no 23.568/2018. Em relação ao Fundo Especial de Financiamento de Campanha - FEFC, os recursos ficam disponíveis para o partido quando são observados os critérios para a distribuição. De acordo com a Lei no 9.504/1997, art. 16-C, § 7ํ, depende de aprovação da maioria de membros da direção nacional partidária, para que sejam distribuídos, enfatizando que 30\% (trinta por cento) da arrecadação deve ser destinada à campanha eleitoral de candidatas. Nota-se um incentivo à presença feminina nos pleitos eleitorais. Os partidos não podem utilizar os recursos do Fundo Partidário, exclusivamente em campanhas de candidatos homens, devido à existência de uma cota de gênero.

Caso esses recursos do Fundo Especial de Financiamento de Campanha sejam utilizados de maneira ilícita, as pessoas beneficiadas são responsabilizadas, de acordo com o art. 30-A da Lei de Eleições (Lei no 9.504/97). É dever dos partidos políticos encaminhar ofício ao Tribunal Superior Eleitoral explicando a distribuição de recursos. 
Em relação aos gastos de campanha, observa-se a previsão de custos com criação e inclusão de sítios na internet e divulgação de conteúdo, sendo contratado provedor com sede no Brasil, conforme dispõe o artigo 26, caput, inciso XV, Lei no 9.504/97. Os itens pessoais do candidato, deixam de ser considerados gastos de campanha, conforme elenca o art. 26, caput, inciso IV e §3ํ, Lei no 9.504/97: Combustível e manutenção veicular; Remuneração, alimentação e hospedagem de motorista e do candidato; Linhas telefônicas de pessoa física.

Esses gastos de campanha, realizados pelos candidatos para comodidade, não precisam ser descritos na prestação de contas. Nesse sentido, não pode ser utilizado recurso do fundo partidário para essa finalidade. A utilização de automóvel do candidato ou de parentes e cônjuges durante esse período também é dispensada.

\section{Fundo Especial de Financiamento de Campanha}

O Fundo Especial de Financiamento de Campanha, chamado popularmente de fundo eleitoral, surgiu a partir de um projeto de lei, cuja aprovação no Senado ocorreu em 26 de setembro de 2017, e na Câmara de Deputados, no dia 5 de outubro do mesmo ano. Tem como objetivo destinar recursos públicos para o custeio das campanhas eleitorais. Através da alimentação com dinheiro do Tesouro Nacional, destina-se à distribuição entre os partidos políticos, para que possam financiar as campanhas eleitorais.

Esse fundo eleitoral se diferencia do fundo partidário, que existe desde 1965, servindo como meio de custeio das atividades cotidianas dos partidos. Com o advento da Lei no 13.487/2017, é criado um fundo que visa compensar as perdas impostas pela decisão do Supremo Tribunal Federal - STF, a Ação Direta de Inconstitucionalidade - ADIn 4.650, que proíbe doações de pessoas jurídicas para os partidos políticos, uma vez que reconhece que o poder econômico pode influenciar negativamente a decisão da eleição.

Assim, se tem uma minirreforma eleitoral, com o advento da Lei no $13.488 / 17$, destinando os recursos públicos para o financiamento de campanha eleitoral. $O$ tema tem causado divergência no universo social, uma vez que a sociedade vem questionando o uso de recursos públicos para essa finalidade. Se de um lado, abastecer os partidos políticos com doações de empresas, tem sido um elemento que fere a democracia, gerando desigualdade entre os candidatos; de outro, a destinação de dinheiro público, diminui a sua aplicação em serviços públicos essenciais para o cidadão.

É certo que o fundo eleitoral surge com a proposta de combater o abuso de poder econômico nas eleições, bem como questões relacionadas à corrupção. A vitória nas urnas, tem sido baseada na troca de vantagens e privilégios ilícitos. Daí a importância de um maior acompanhamento, por parte da Justiça Eleitoral. Com a Ação Direta de Inconstitucionalidade no 4.650 do STF, ajuizada pelo Conselho Federal da Ordem dos Advogados do Brasil - CFOAB, ficou vedada qualquer doação de recursos para fins eleitorais, por empresas. Essa medida originou a Lei no 13.487/2017, que cria o Fundo Especial de Financiamento de Campanha. Nesse sentido, o modelo de financiamento previsto na Lei no 9.504/97 e na Lei no 9.096/95, passou a ser inconstitucional.

A fundamentação da inconstitucionalidade, encontrada na Lei das Eleições e na Lei dos Partidos 
Políticos, está no fato desse tipo de financiamento de campanha eleitoral ser prejudicial ao pleito, uma vez que as empresas exerciam um poder econômico na decisão, sempre buscando o favorecimento após a vitória nas urnas. A elite econômica financiava a campanha por meio de pessoas jurídicas, em defesa de interesses individualizados, rompendo com a proposta de garantir o bem comum.

A política tornava-se dependente economicamente das empresas, que investiam altos valores nas campanhas eleitorais, em troca de benefícios futuros. Com a participação de pessoas jurídicas na arrecadação de recursos para a campanha, são violados os princípios constitucionais: da isonomia, democracia, república e proporcionalidade. Não há a proteção necessária para que o pleito atenda aos anseios e necessidades sociais. Entende-se que a sociedade empresarial objetiva o lucro e não tem ações que defendam os interesses da população. O financiamento de campanhas políticas tem como finalidade o alcance de vantagens, sendo essa a razão da inconstitucionalidade dessa forma de arrecadação de recursos. Com a decisão do STF, analisando a Ação Direita de Inconstitucionalidade no 4650, os partidos políticos tiveram que buscar alternativas para arrecadar recursos para as campanhas, aprovando o Fundo Especial de Financiamento de Campanhas - FEFC, cujo valor estimado é de R\$ 1,7 bilhão.

\section{CONCLUSÕES}

Com o presente estudo, foi possível verificar que a legislação eleitoral sofreu algumas modificações significativas em relação a arrecadação e aplicação dos recursos de campanha. Uma das mudanças mais significativas diz respeito à criação do Fundo Especial de Financiamento de Campanhas (FEFC), uma forma de financiamento que utiliza recursos públicos. Entre as formas de financiamento, estão o FEFC, o fundo partidário, doações de pessoas físicas e autofinanciamento dos candidatos.

No decorrer do estudo, foi observado que as doações de pessoas físicas possuem limites, uma vez que não deve ultrapassar 10\% (dez por cento) de seus rendimentos. Essa iniciativa de tornar o processo eleitoral mais justo e igualitário, combatendo ações corruptas, transferiu para a sociedade o ônus e a responsabilidade por esse financiamento. Diante dos desafios encontrados, verifica-se que o maior é a fiscalização, vedando qualquer forma de caixa dois ou troca de favores após a vitória nas urnas.

Os recursos do Fundo Eleitoral são distribuídos entre os partidos políticos, para que os candidatos possam requerer por escrito ao órgão a acessibilidade. As doações por pessoas físicas podem ser realizadas em dinheiro, ou bem móveis e imóveis. Hoje, o Brasil tem como modelo de financiamento de campanha o misto, que é entendido pelos doutrinadores, que serviram de base para o entendimento da problemática, como o mais adequado.

Por fim, conclui-se que o Fundo Especial de financiamento de Campanha Eleitoral, cuja criação é baseada na Lei № 13.487/2017 e na Lei no 13.844/2017, utiliza recursos públicos no financiamento de partidos políticos e candidatos, sendo uma alternativa para a impossibilidade de financiamento privado por empresas. Cabe aos órgãos partidários distribuir a verba, dentro dos requisitos estabelecidos por lei. 


\section{REFERÊNCIAS}

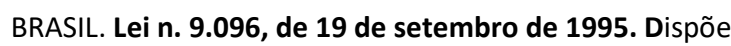
sobre partidos políticos, regulamenta os arts. 17 e 14 , § 3ㅇ, inciso V, da Constituição Federal. Brasília: DOU, 1995.

BRASIL. Lei $\mathbf{n . ~ 9 . 5 0 4 , ~ d e ~} 30$ de setembro de 1997. Estabelece normas para as eleições. Brasília: DOU, 1997.

BRASIL. Lei n. 13.165, de 29 de setembro de 2015. Altera as Leis $\mathrm{n} 09.504$, de 30 de setembro de 1997, 9.096, de 19 de setembro de 1995, e 4.737, de 15 de julho de 1965 - Código Eleitoral, para reduzir os custos das campanhas eleitorais, simplificar a administração dos Partidos Políticos e incentivar a participação feminina. Brasília: DOU, 2015.

BRASIL. Lei n. 13.487, de 06 de outubro de 2017. Altera as Leis $\mathrm{n} \cong 9.504$, de 30 de setembro de 1997, e 9.096, de 19 de setembro de 1995, para instituir o Fundo Especial de Financiamento de Campanha (FEFC) e extinguir a propaganda partidária no rádio e na televisão. Brasília: DOU, 2017a.

BRASIL. Lei n. 13.488, de 6 de outubro de 2017. Altera as Leis $\mathrm{n}$ ㅇ.9.504, de 30 de setembro de 1997 (Lei das Eleições), 9.096, de 19 de setembro de 1995, e 4.737, de 15 de julho de 1965 (Código Eleitoral), e revoga dispositivos da Lei no 13.165, de 29 de setembro de 2015 (Minirreforma Eleitoral de 2015), com o fim de promover reforma no ordenamento político-eleitoral. Brasília: DOU, 2017b.

CARVALHO, F.. História do Brasil. São Paulo: Companhia de Letras, 2020.
CÂNDIDO, J. J.. Direito Eleitoral Brasileiro. 6 ed. Bauru: Edipro, 2008.

COSTA, E. F.. Direito Eleitoral. Rio de Janeiro: Forense, 2016.

FURTADO, L. B.. Os efeitos da Resolução n. 22.874/2008 do TSE. São Paulo: Universitária, 2014.

FURTADO, L. B.. Direito eleitoral. São Paulo: Universitária 2016.

GONÇALVES, C. V.. Incompetência do município para legislar sobre propaganda eleitoral. São Paulo: Universitária, 2016.

OLIVEIRA, T. A.. O financiamento de campanhas eleitorais no Brasil: histórico, atualidade e a questão na Suprema Corte. Brasília: Universitária, 2019.

OLIVEIRA, T. A.. Direito Eleitoral. São Paulo: Universitária, 2020.

SALGADO, A.. Ação Civil Pública: Defesa do Patrimônio Público e da Moralidade Administrativa. Revista dos Tribunais, v.86, n.735, p.161-172, 2014.

SANTANO, A. C.. O procedimento para o financiamento de campanhas eleitorais e a problemática da prestação de contas dos recursos utilizados. São Paulo: Revista dos tribunais, 2016.

A CBPC - Companhia Brasileira de Produção Científica (CNPJ: 11.221.422/0001-03) detém os direitos materiais desta publicação. Os direitos referem-se à publicação do trabalho em qualquer parte do mundo, incluindo os direitos às renovações, expansões e disseminações da contribuição, bem como outros direitos subsidiários. Todos os trabalhos publicados eletronicamente poderão posteriormente ser publicados em coletâneas impressas sob coordenação da Sustenere Publishing, da Companhia Brasileira de Produção Científica e seus parceiros autorizados. Os (as) autores (as) preservam os direitos autorais, mas não têm permissão para a publicação da contribuição em outro meio, impresso ou digital, em português ou em tradução. 